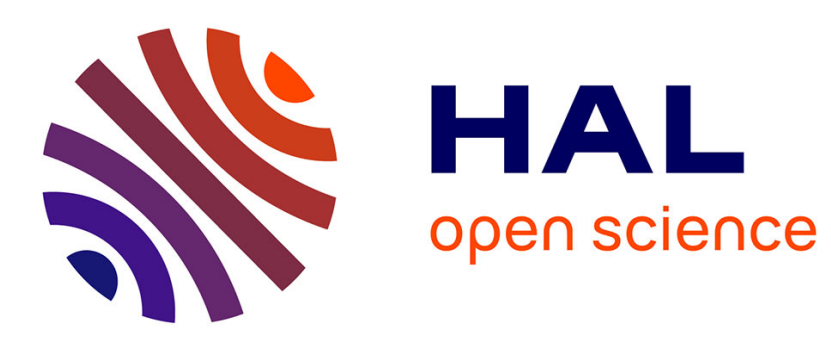

\title{
Development of a Co-Simulation System as a Decision-Aid in Lean Tools Implementation
}

\author{
Jalal Possik, Aicha Amrani, Grégory Zacharewicz
}

\section{To cite this version:}

Jalal Possik, Aicha Amrani, Grégory Zacharewicz. Development of a Co-Simulation System as a Decision-Aid in Lean Tools Implementation. 2018 Summer Simulation Multi-Conference, Jul 2018, Bordeaux, France. 10.22360/summersim.2018.scsc.037 . hal-01907690

\section{HAL Id: hal-01907690 \\ https://hal.science/hal-01907690}

Submitted on 3 Dec 2019

HAL is a multi-disciplinary open access archive for the deposit and dissemination of scientific research documents, whether they are published or not. The documents may come from teaching and research institutions in France or abroad, or from public or private research centers.
L'archive ouverte pluridisciplinaire HAL, est destinée au dépôt et à la diffusion de documents scientifiques de niveau recherche, publiés ou non, émanant des établissements d'enseignement et de recherche français ou étrangers, des laboratoires publics ou privés. 


\title{
DEVELOPMENT OF A CO-SIMULATION SYSTEM AS A DECISION-AID IN LEAN TOOLS IMPLEMENTATION
}

\author{
Jalal Joseph Possik \\ Laboratoire IMS UMR CNRS 5218 \\ Groupe Productique \\ Université de Bordeaux \\ 351 cours de la Libération, \\ 33405 Talence cedex, France \\ jalal.possik@u-bordeaux.fr
}

\author{
Aicha Anne Amrani \\ Laboratoire IMS UMR CNRS 5218 \\ Groupe Productique \\ Université de Bordeaux \\ 351 cours de la Libération, \\ 33405 Talence cedex, France \\ aicha.amrani@ims-bordeaux.fr
}

\author{
Gregory Zacharewicz \\ Laboratoire IMS UMR CNRS 5218 \\ Groupe Productique \\ Université de Bordeaux \\ 351 cours de la Libération, \\ 33405 Talence cedex, France \\ gregory.zacharewicz@ims-bordeaux.fr
}

\begin{abstract}
Aside from the human and managerial skills necessary to propel any business, the right Lean deployment can play a big role in reducing waste and maximizing efficiency. Capturing these benefits is highly dependent on adequate Lean techniques integration. Companies shifting towards Lean conversion have tried one of many Lean Manufacturing optimization tools at their disposal today (JIT, Pull System, U cells, CrossTraining, Visual Management, SMED, Poka Yoke, etc.) hoping to capture the benefits of such conversion. One of the major hurdles these companies face is the difficulty to choose the Lean tools that best fit their economic contexts and that are best tailored towards reaching their productivity or quality milestones. The Discrete Event Simulation becomes an interesting approach, to imitate the evolution of a manufacturing system and to represent the transformation induced by the Lean tools integration in the manufacturing line. The system developed in this paper is a Co-Simulation system. It is built based on a two-level structure. The first level is a basic framework for modeling the manufacturing assembly line with its various components (using JaamSim), while the second is a hierarchical framework for executing parallel Lean Tools simulations (using MECSYCO). To demonstrate the usefulness of this Co-Simulation system, an example of an Aeronautic Assembly Line is used. Three Lean Configuration Scenarios are investigated under market fluctuation context (Batch Policy, Setup times reduction with SMED, Pull System), compared with an Actual model simulated as a Lean Free scenario.
\end{abstract}

Keywords: Lean Manufacturing, Lean tools and techniques, Discrete Event Simulation, Co-Simulation, Key Performance Indicator. 


\section{INTRODUCTION}

Scientific publications pointed out the effectiveness of Lean implementation in different companies, services, departments, supply chain, production workshops and assembly lines. Research strongly supports the benefits of Lean manufacturing approach in optimizing a company's performance (Bhasin, 2012; Laureani \& Antony, 2012). However, Lean implementation has experienced many failures (Nordin, Deros, \& Wahab, 2010; R. Jadhav, S. Mantha, \& B. Rane, 2014). The recent research lead by Mirdad et al. (Mirdad \& Eseonu, 2015) suggested a conceptual Lean map that could assist with a better Lean implementation in minimization of Lean misuse. The actual challenge is to understand and appropriately implement Lean concepts well-tailored to the company's current economic contexts and future projections (Sarhan \& Fox, 2013). Managers and engineers are in continuous search for supported methodology and cross analysis for effective Lean use (Mirdad \& Eseonu, 2015). Moreover, the literature is abundant with cases where Lean is successfully or unsuccessfully implemented. Some authors tried to catalog these success stories and failures in order to use them in similar environments.

These cases and empirical findings cannot be reliably scalable to be applied ubiquitously in similar scenarios. Consequently, simulation related researches help tackle and solve this actual problem. In (Olhager \& Persson, 2006), the author outlined the necessity for thoroughly understanding the nature of manufacturing operations to achieve the Lean and operational excellence target. Thus, simulation is by nature an added value analysis approach because it allows testing many possible scenarios without real implementation which saves time and money. In our paper, we built a Co-Simulation system that monitors the behavior of a production line based on multiple models simulated simultaneously to check and compare the respective system output in an interesting graphical way. Furthermore, for each iteration we vary the economic context and based on the results, we choose the best Lean tool behavior to be subsequently applied in similar cases.

This paper is structured as follows: in section 2 the literature review is used to position our work. Section 3 introduces the built simulation system, its constraints and targets, its manufacturing context, as well as its initial data inputs. Section 4 shows the experimental protocols, analysis and the issued results. A comprehensive graph illustrates the chosen key performance indicators for this study: WIP (Work In Progress), SKU (Stock Keeping Unit), Material Buffers and Lead-times. Subsequently, results will be analyzed and discussed. Finally, further research experimentations are highlighted to define the framework of coming future simulations.

\section{LITERATURE REVIEW}

Simulation Field encompasses broad methods that are able to imitate the behavior of real systems (Detty \& Yingling, 2000). The simulation development process starts by defining the problem and the system, formulating the conceptual model, designing the initial experiment, collecting and preparing the data and by translating, verifying and validating the model (Kelton, Sadowski, \& Sturrock, 2007). The next phases will be to design and run the experiments, analyze and interpret the results, and finally, document the output results. The simulation in Manufacturing and Supply Chain fields became a very widespread scientific approach since early 2000's (Jain, Choong, \& Lee, 2002) because of the ability to reproduce a virtual system that simulates the real production system (Long, 2014), in addition to a "What If" analysis of different scenarios that observes and understands the Supply Operations (Chatfield, Harrison, \& Hayya, 2006; Zhao \& De Souza, 2000) and forecasts the impact of alternative configurations (Tan, Chai, \& Liu, 2011).

The Discrete-Event Simulation (DES), in particular, is one of the preferred research topics nowadays (Yoo, Cho, \& Yücesan, 2010) for its ability to simulate production system and supply chain behaviors (Zengin, 2011; Zengin, Sarjoughian, \& Ekiz, 2013). DES was often considered as a dynamic tool that allows the visualization and quantification of technological and operational changes in processes (Julie Yazici, 2005). DES is suitable for leading analysis of the dynamics of discrete processes such as manufacturing systems 
(Ingemansson \& Bolmsjö, 2004) and the possibility to run different scenarios in a short period of time (Banks, 1998).

Jeon et al. (Jeon \& Kim, 2016) remind that DES for Production Planning and Control problems is a frequently used tool that represents more than $45 \%$ of the simulation models in the studied sample. Further studies have made the attempt of combined methods as DES and Agent technology for studying complex supply network (Alavi-Moghaddam et al., 2012) to be able to integrate micro-behaviors of individuals and macro system to guide the managers in their decision-making process. In a complex production environment with a complex demand evolution, many authors use DES to quantify the effect of VSM implementation on Lean performance measures, such as work in process and lead time (Abdulmalek \& Rajgopal, 2007; Detty \& Yingling, 2000). Along the same line, our choice is to focus on WIP, Lead-times, material buffers and the SKU. Indeed, the SKU represents the level of end-products that the company has to plan and control in each Lean tools configuration scenario. It provides a quick appreciation of the global storage in the facilities and Plants.

Early studies confirmed the benefit of Lean tool use in the right context. The relationship between Cellular Manufacturing (CM) and flexibility of products was investigated and remains unclear (Hulya, 2005). Cells were found to be flexible to volume fluctuations and withstand changes over time (Hulya, 2005; Wemmerlov \& Johnson, 2000). Since, the performance advantage of CM and manufacturing flexibilities has not been clearly demonstrated, and several questions remain unanswered. One question is, how is the delivery lead time affected by volume, mix, routing, and labor flexibilities? In (Kück, Ehm, Freitag, Frazzon, \& Pimentel, 2016), the demand variation going beyond $20 \%$ is investigated, and the level of storage is explored and found to be significantly reduced after a period of time. This finding is corroborated with the previous study of (Agarwal, Shankar, \& Tiwari, 2006) which confirms that Lean SCM practices are preferably adopted within contexts where the variability tends to be lower, and where there are frequent changes in customer demand. To reiterate, the notion of context influence in the choice of the Lean practices reinforces our approach combining both context and simulations. We subscribe to the idea of checking the relevance of tools regarding the economic environment. Still, new insights and analysis are required to better perceive the interest of Lean practices implementation.

Simulation models discussed in this paper are designed in JaamSim. This software is used in this research instead of other simulation software, because of its transparency, reliability, capability and most importantly because it is an open-source software and can be configured to interact with third-party applications. In order to implement our Co-Simulation system, MECSYCO (Multi-agent Environment for Complex SYstem CO-simulation) was used. It is an open-source framework which supports Java and C++ programming languages to manage complex simulation models. It also has the MECSYCO-visu package that helps visualize simulation events in real time and shows output data in $2 \mathrm{D}$ graphs, pie charts or other visualization forms.

\section{MANUFACTURING CONTEXT}

As per Figure 1, The developed Co-simulation system has the objective to simulate the manufacturing assembly line undergoing different economic contexts so that we can choose the best Lean tool that reacts better to such context variation. In this paper, Demand Fluctuation context is tested.

As outlined in (Detty \& Yingling, 2000) and as analyzed in our work, some Lean practices are Engineering related and can be configured and parametrized, while, others are not. Kanban, SMED, Cross Training, Poka Yoke, Cellular Manufacturing, 5S can be modeled and simulated. However, human-related Lean tools are inimitable technically in simulation models. Those include kaizen, employee commitment, leadership, direction management, empowerment, continuous improvement. The aim of this paper is to focus on Pull System (Kanban), Setup time reduction (SMED) and Batch strategy. The assessment of Lean tools configuration consistency regarding the economic context is achieved through four KPI: Key Performance 
Indicators. The global lead-times, WIP, SKU and Material Buffers are used to evaluate the performance of the manufacturing assembly line.

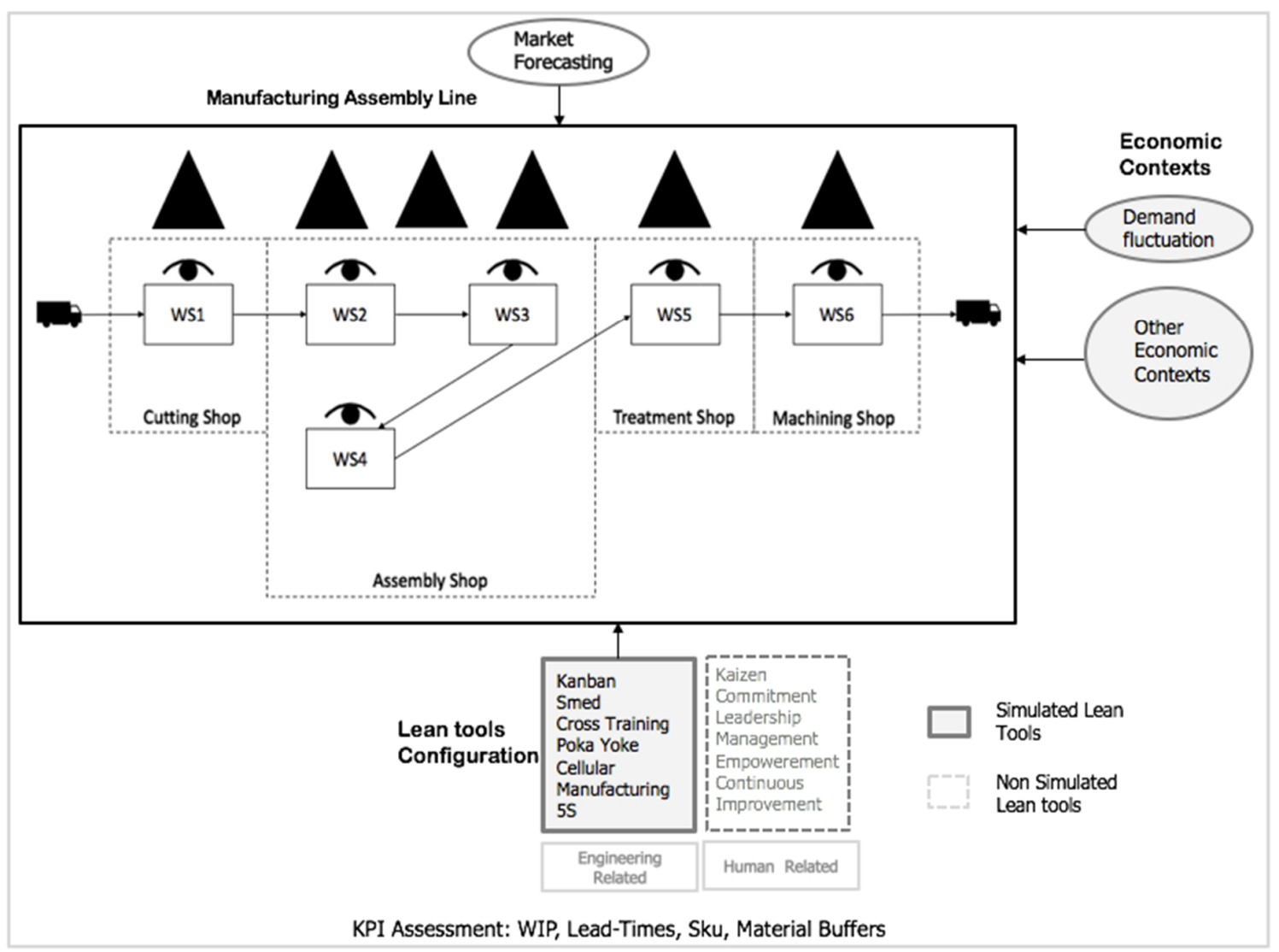

Figure 1: Manufacturing Simulated Context.

\section{SYSTEM ARCHITECTURE}

\subsection{Co-Simulation Configuration}

MECSYCO is an agent-based system that simulates, in parallel and simultaneously, interactions and operations of multiple agents. In our case, it is used as an orchestrator for all the models and simulations developed using JaamSim. It launches the simulations, captures respective simulations times and outputs data, synchronizes time between simulations, simultaneously sketches the output data to graphs, and finishes all the simulations when the maximum simulation time, defined by the variable maxSimulationTime, is reached. As per Figure 2, each model is linked to a specific agent and Model Artifact responsible for sending and receiving data from the simulators. Jaamsim configuration file and output of each model, are sent respectively to Model Artifacts. Each model represents a specific configuration of the assembly line where models represent the Lean tools to be tested: SMED, Batch Policy, Pull System, and the Actual model representing the Lean Free scenario. 
public class Launcher \{

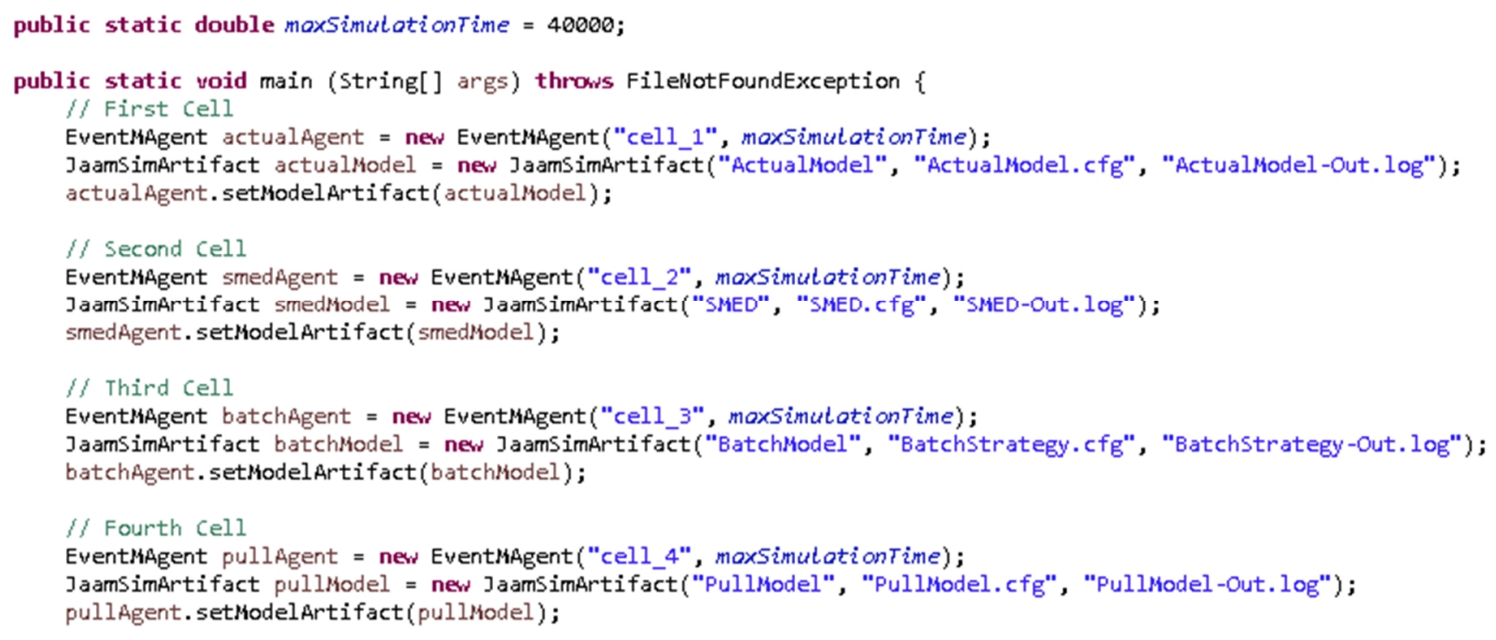

Figure 2: Multi-Agent configuration.

\subsection{Interface Configuration}

In this proposed Co-Simulation system's architecture, as per Figure 3, the user inserts the input data used by the four existing models and launches the system through a web interface developed using Node.js which will initiate all the models simultaneously, get the data and time from each model, and draw graphs representing real-time outputs. This Co-Simulation system will be a decision-aided system to select the best model that suits the organization production and financial targets. Furthermore, these models and results will be cataloged and used as references for companies facing similar future situations.

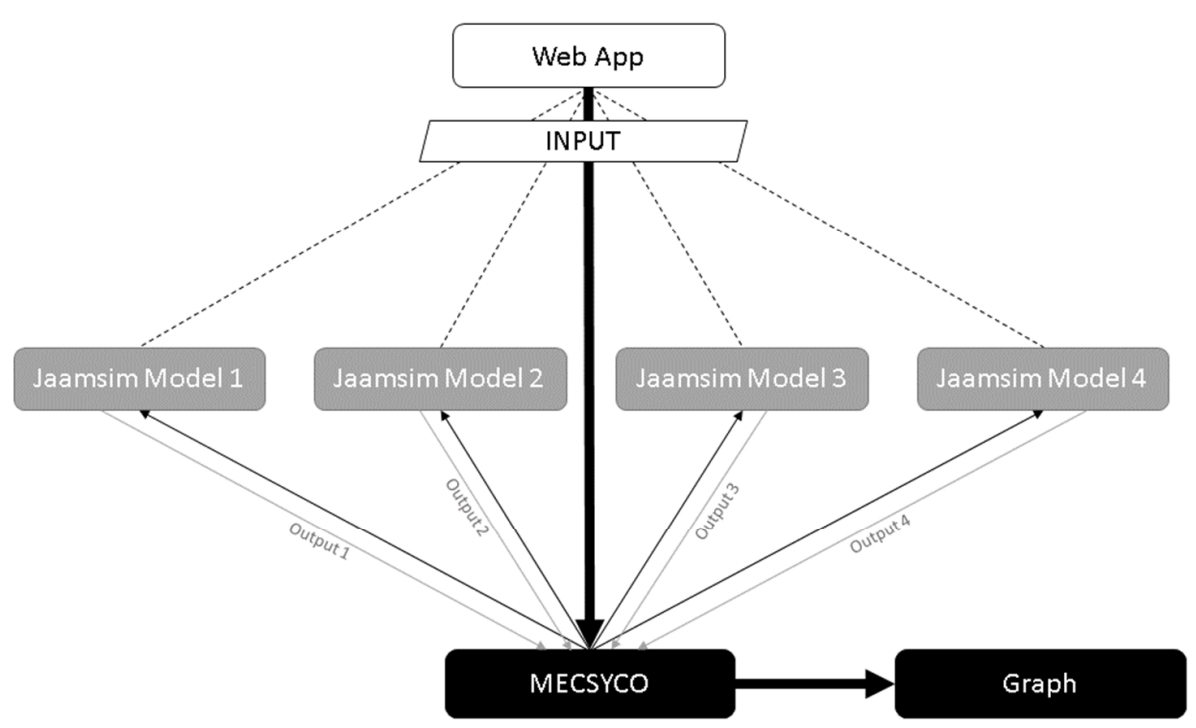

Figure 3: Co-System Architecture. 
The simulated manufacturing assembly line issued from Aeronautic Industry represents a $2^{\text {nd }}$ Tier supplier providing aeronautic fasteners. Ten Final Product references are items assembled in-house. Demand is assumed to be stochastic. Ten raw materials types are used to start the assembly of aeronautic fasteners. The manufacturing facility is an assembly Line (items are manufactured by subcontractors) and the ten references are assembled undergoing a flow shop consisting of five workshops with limited human capacity. As initial data, the input parameters identify the Demand distributions, workshops production times and setup times. The simulation will be executed on a one year order book.

Initial Data settings are filled into a web interface as per Figure 4, the user enters the Setup Time and Processing Time for each Machine (WS1, WS2..., WS6). Then, the user can choose the yearly demand for each product type by, selecting the type (Type 1, Type 2..., Type 10), randomizing the demand for each month, and if needed, changing the demand for each day in the month. By clicking on Submit, the system launches the Co-Simulation of the four developed models. Currently, the web interface is only used to provide the Input data (Setup Times, Processing Times and yearly order book) to the simulators. For future improvements, we are planning to add the output graph and results, provided by the Co-Simulation system, to the web interface. In this paper, we considered that simulations run without machine downtime.

\section{SIMULATION PARAMETERS}

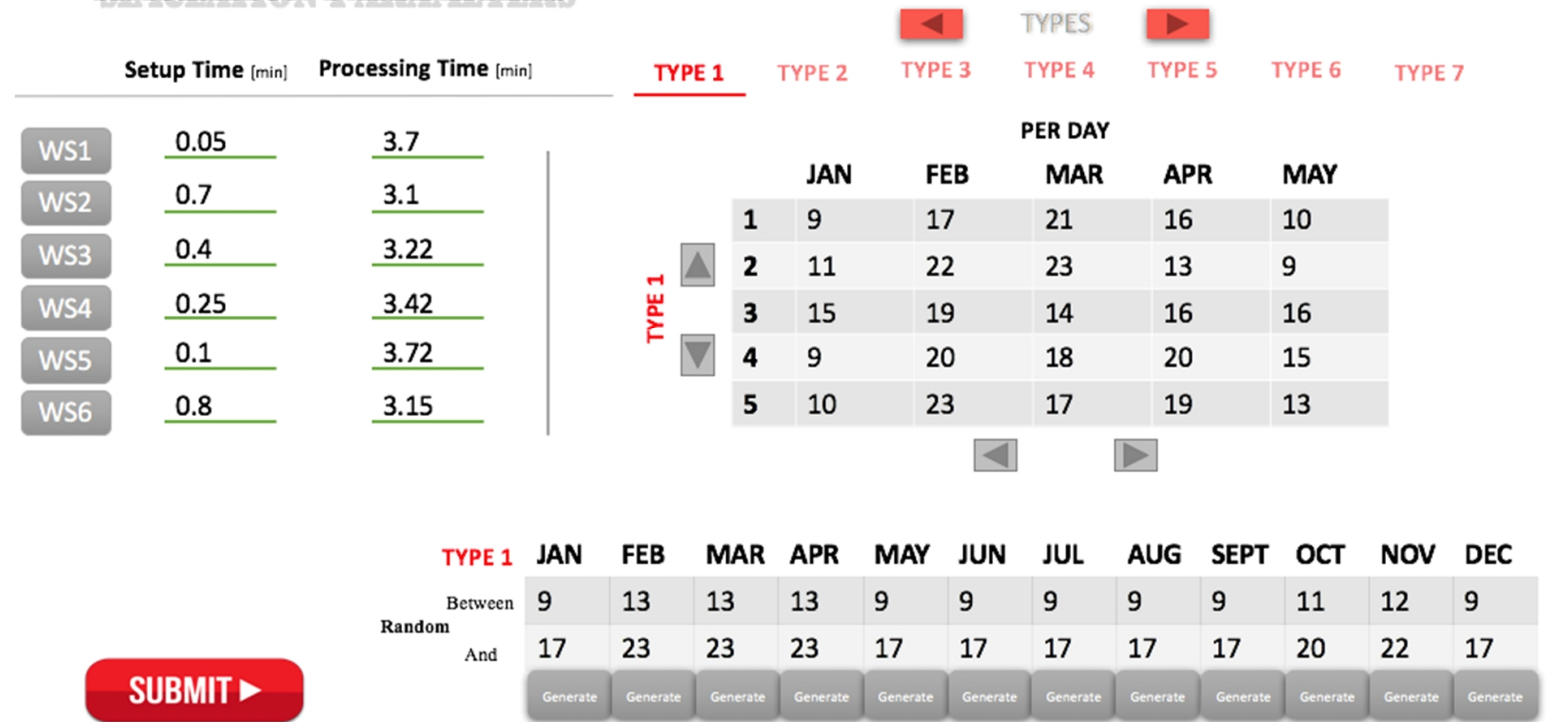

Figure 4: Web Interface, Input Parameters.

\subsection{Models Configuration}

Ten Entity Generators are created to generate ten different types of Raw Materials, See Figure 5. The Raw Material generation is based on the yearly order demand filled in the Web Interface. Raw Materials are then sent to the Machine (WS1) in the Cutting Shop. WS1 machine has a Setup Time and a Processing Time defined also in the Web Interface. After being processed, goods are sent to WS2, and so on until the delivery process. Entity Conveyors are used to specify the travel time between machines. WIP1 is the Work In Progress of the First Machine, WIP2 is the Work In Progress for the second Machine, and so on. The same model structure is used for the remaining three models. For Batch Strategy scenario configuration, Raw Materials are set in batches before being processed. For SMED scenario, each machine setup time is reduced by a certain percentage. As for Pull scenario configuration, each machine sends a signal to the upstream one when its WIP exceeds three units to stop sending products in process. 


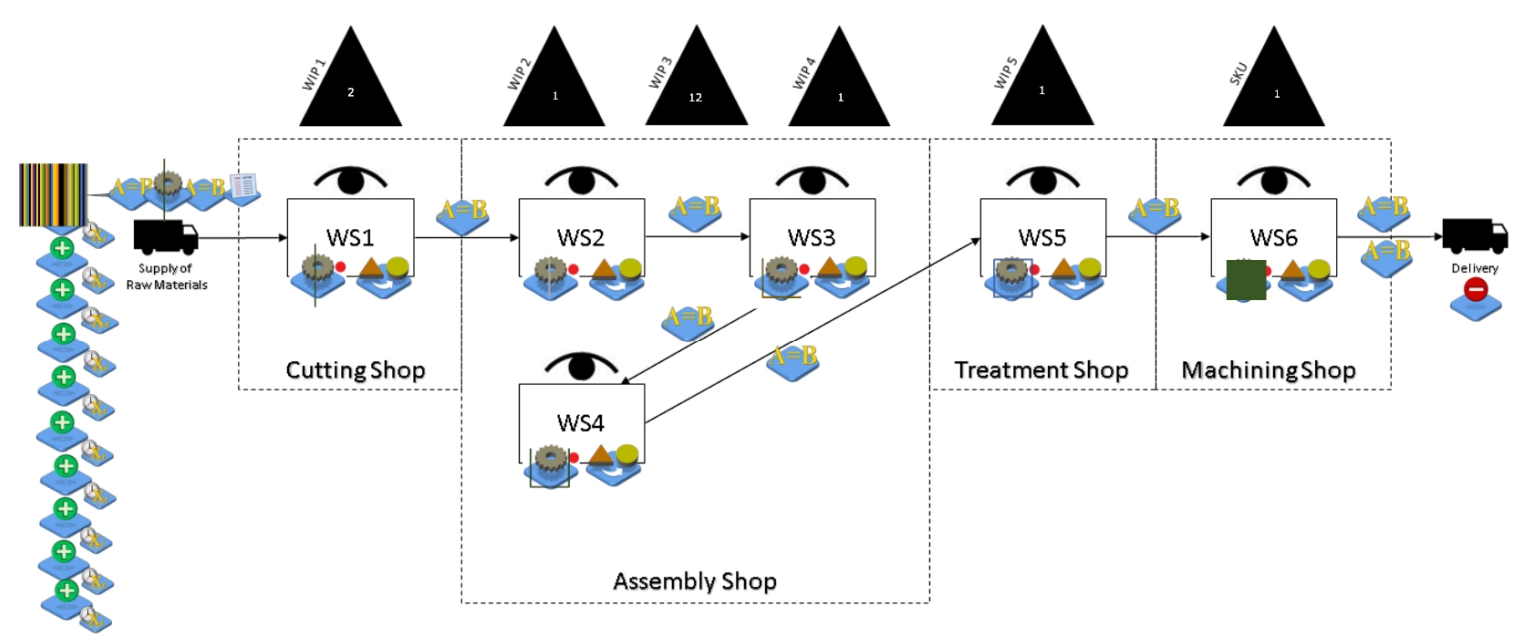

Figure 5: Simulation Model Interface.

Simulations outputs are communicated simultaneously, during the simulation process, to the respective Model Artifacts and agents created using MECSYCO, then generated simultaneously into real-time graphs. Four outputs, global lead-times, WIP, SKU and Material Buffers are configured for four configuration scenarios. Table 1 summarizes the input and output parameters used for this Co-Simulation.

Table 1: Input and Output Parameters.

Input Parameters

- Stochastic Yearly Demand

- Randomly Generated Demand

Initial Data - Production time per shop

- Setup time per Machine

- Deterministic Raw Materials Supply
Output Parameters

- WIP average

- Overall Lead-times

- SKU

- Material Buffers

\begin{tabular}{|c|c|c|c|c|c|}
\hline & & & Uptime & Setup Time [min] & Processing Time [min] \\
\hline \multirow{6}{*}{$\begin{array}{l}\text { Assembly } \\
\text { Line Data }\end{array}$} & Cutting shop & WS1 & $100 \%$ & 0.05 & 3.7 \\
\hline & & WS2 & $100 \%$ & 0.7 & 3.1 \\
\hline & & WS3 & $100 \%$ & 0.4 & 3.22 \\
\hline & Assembly shop & WS4 & $100 \%$ & 0.25 & 3.42 \\
\hline & Treatment shop & WS5 & $100 \%$ & 0.1 & 3.72 \\
\hline & Machining shop & WS6 & $100 \%$ & 0.8 & 3.15 \\
\hline
\end{tabular}




\section{EXPERIMENTATION RESULTS AND DISCUSSIONS}

We started by simulating the four discussed models in parallel for the initial situation of the organization's assembly line, without any economic context variations. As per Figure 6, we can see that the actual model has an excess WIP considered as a waste, this waste is caused by bottlenecks in the production process. After a simulation time equivalent to one year of production, WIP of the actual model exceeded 2000 units in the production facilities. SMED and Batch implementations minimized the WIP but the Pull scenario yielded the best results. Pull Model also yielded the best global Lead-time average. Concerning Material Buffers which are raw materials waiting for production, the batch strategy showed the best result in terms of production speed and setup time reduction. On the other hand, the SKU issue was solved in the three developed Lean scenarios as shown in Figure 6.

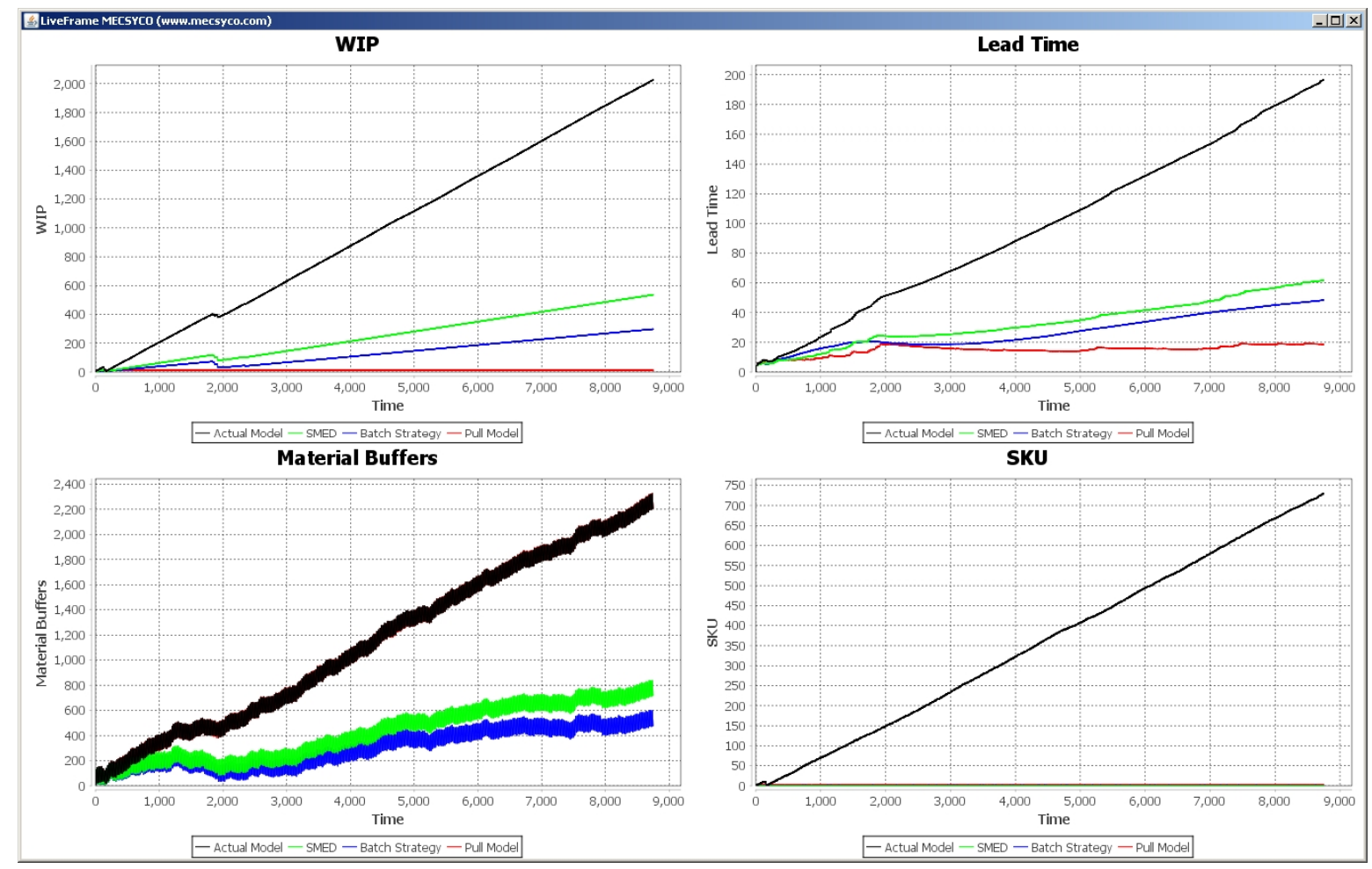

Figure 6: Parallel Output Graphs.

In this paper, we tested the Demand Fluctuation economic context, by increasing the market demand by $50 \%$ during February, March and April in the first simulation iteration then decreasing the demand by $50 \%$ for the same months in the second one. After a simulation time equivalent to one year of production, we got the results shown in Table 2. We conclude that, by decreasing the market demand, Batch strategy, which is not a Lean technique, and SMED scenario gave almost the same good results. In fact, as market demand drops, less production is required. This alleviates the constraints on the assembly line which justified the results discussed above. However, by increasing the market demand, batch strategy gave bad results with an almost doubling in the lead-time average when compared to the actual model. This in return will delay customers' orders delivery. In Figure 7, we see that Batch Strategy started to increase at time $1000 \mathrm{~h}$, equivalent to the second half of February, and gets to $820 \mathrm{~h}$ of lead-time average after one year, which is $320 \mathrm{~h}$ of lead-time average more than the actual model. This analysis strengthens the relevance of both Lean tools, Pull and SMED, in coping with unpredictable ramp in production. 
Table 2: Market Fluctuation Context and Lean tools configurations relevancy.

Initial Situation

1 Year Simulation

10 References

\begin{tabular}{lcccc}
\hline & WIP (u) & Lead Time (hours) & Material Buffers (u) & SKU (u) \\
\cline { 2 - 5 } Actual Model & 2110 & 210 & 2300 & 725 \\
Batch Strategy & 360 & 62 & 550 & 1 \\
Pull Model & 13 & 17 & 2300 & 2 \\
SMEI & 600 & 70 & 800 & 1
\end{tabular}

Economic Context

Market Fluctuation $\mid+50 \%$ of demand increase FEB MAR APR

\begin{tabular}{lcccc} 
& WIP (u) & Lead Time (hours) & Material Buffers (u) & SKU (u) \\
\cline { 2 - 5 } Actual Model & 2110 & 500 & 2300 & 725 \\
Batch Strategy & 360 & 820 & 550 & 1 \\
Pull Model & 13 & 320 & 2300 & 2 \\
SMIED & 600 & 370 & 800 & 1
\end{tabular}

Economic Context

Market Fluctuation | -50\% of demand decrease FEB MAR APR

\begin{tabular}{lcccc}
\hline & WIP (u) & Lead Time (hours) & Material Buffers (u) & SKU (u) \\
\cline { 2 - 5 } Actual Model & 1800 & 180 & 2200 & 750 \\
Batch Strategy & 200 & 30 & 500 & 1 \\
Pull Model & 13 & 17 & 2200 & 2 \\
SMED & 380 & 32 & 650 & 1
\end{tabular}




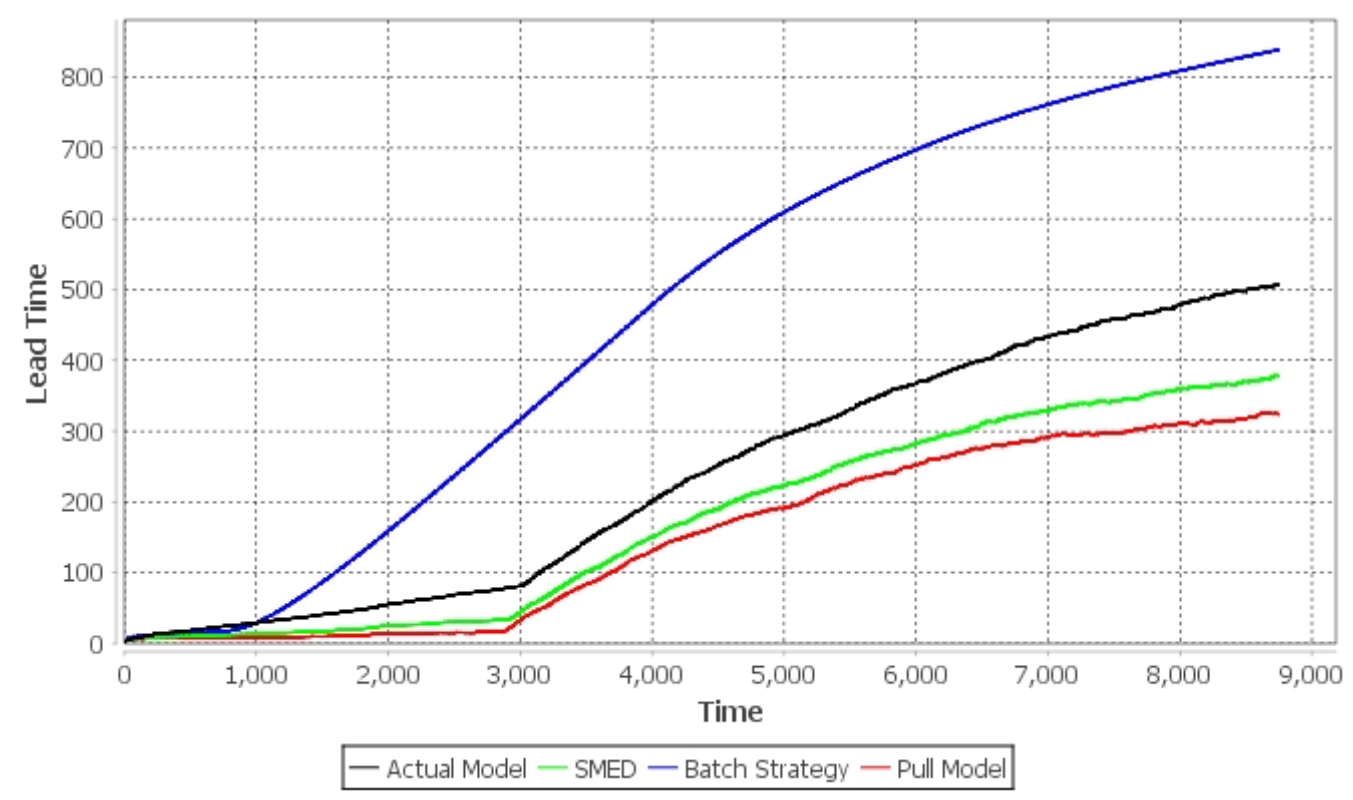

Figure 7: Lead-time of the Batch Strategy with 50\% increase in Market Demand on FEB, MAR, APR.

\section{CONCLUSION AND PERSPECTIVES}

The use of MECSYCO broadens our horizons and opens the door for multiple models developed in different and heterogeneous simulators, to be added to our system. As shown in this paper, our study was limited to four simultaneous simulation scenarios due to process power limitation. As future work and improvement, Distributed Simulations will be developed to solve this problem; it allows for different simulations to be run simultaneously on different processors available on a network, opening the door for unlimited testing capabilities. The use of Distributed Simulations will enable us to create and run multiple Lean scenarios over a broad processors' network. The hypothesis test of the relevance of Lean techniques in different market contexts will be investigated in depth. The goal is to expand the built Co-Simulation System to gradually integrate other Lean techniques. Using our system, we can introduce modifications and disruptions in many variables from conception to commercialization (quality defect, machine downtime, mix flexibility of market, etc.). Running our system will allow us to track the behavior of different Lean tools and techniques and determine the most suited Lean Tools accordingly.

\section{REFERENCES}

Abdulmalek, F. A., \& Rajgopal, J. (2007). Analyzing the benefits of lean manufacturing and value stream mapping via simulation: A process sector case study. International Journal of Production Economics, 107(1), 223-236.

Agarwal, A., Shankar, R., \& Tiwari, M. (2006). Modeling the metrics of lean, agile and leagile supply chain: An ANP-based approach. European Journal of Operational Research, 173(1), 211-225.

Alavi-Moghaddam, M., Forouzanfar, R., Alamdari, S., Shahrami, A., Kariman, H., Amini, A., et al. (2012). Application of queuing analytic theory to decrease waiting times in emergency department: does it make sense? Archives of trauma research, 1(3), 101.

Banks, J. (1998). Handbook of simulation: principles, methodology, advances, applications, and practice: John Wiley \& Sons.

Bhasin, S. (2012). An appropriate change strategy for lean success. Management Decision, 50(3), 439458.

Chatfield, D. C., Harrison, T. P., \& Hayya, J. C. (2006). SISCO: An object-oriented supply chain simulation system. Decision Support Systems, 42(1), 422-434. 
Detty, R. B., \& Yingling, J. C. (2000). Quantifying benefits of conversion to lean manufacturing with discrete event simulation: A case study. International Journal of Production Research, 38(2), $429-445$.

Hulya, J. Y. (2005). Influence of flexibilities on manufacturing cells for faster delivery using simulation. Journal of Manufacturing Technology Management, 16(8), 825-841.

Ingemansson, A., \& Bolmsjö, G. S. (2004). Improved efficiency with production disturbance reduction in manufacturing systems based on discrete-event simulation. Journal of Manufacturing Technology Management, 15(3), 267-279.

Jain, S., Choong, N. F., \& Lee, W. (2002). Manufacturing supply chain applications: modeling computer assembly operations for supply chain integration. Paper presented at the Proceedings of the 34th conference on Winter simulation: exploring new frontiers.

Jeon, S. M., \& Kim, G. (2016). A survey of simulation modeling techniques in production planning and control (PPC). Production Planning \& Control, 27(5), 360-377.

Julie Yazici, H. (2005). Influence of flexibilities on manufacturing cells for faster delivery using simulation. Journal of Manufacturing Technology Management, 16(8), 825-841.

Kelton, W., Sadowski, R., \& Sturrock, D. (2007). Simulation with Arena. New York: McGrawHill: Inc.

Kück, M., Ehm, J., Freitag, M., Frazzon, E. M., \& Pimentel, R. (2016). A Data-driven Simulation-Based Optimisation Approach for Adaptive Scheduling and Control of Dynamic Manufacturing Systems. Paper presented at the Advanced Materials Research.

Laureani, A., \& Antony, J. (2012). Critical success factors for the effective implementation of Lean Sigma. International Journal of Lean Six Sigma, 3(4), 274-283.

Long, Q. (2014). Distributed supply chain network modelling and simulation: integration of agent-based distributed simulation and improved SCOR model. International Journal of Production Research, 52(23), 6899-6917.

Mirdad, W. K., \& Eseonu, C. I. (2015). A Conceptual Map of the Lean Nomenclature: Comparing Expert Classification to the Lean Literature. Engineering Management Journal, 27(4), 188-202.

Nordin, N., Deros, B. M., \& Wahab, D. A. (2010). A survey on lean manufacturing implementation in Malaysian automotive industry. International Journal of Innovation, Management and Technology, 1(4), 374.

Olhager, J., \& Persson, F. (2006). Simulating production and inventory control systems: a learning approach to operational excellence. Production Planning \& Control, 17(2), 113-127.

R. Jadhav, J., S. Mantha, S., \& B. Rane, S. (2014). Exploring barriers in lean implementation. International Journal of Lean Six Sigma, 5(2), 122-148.

Sarhan, S., \& Fox, A. (2013). Barriers to Implementing Lean Construction in the UK Construction Industry (Vol. Volume 6).

Tan, W., Chai, Y., \& Liu, Y. (2011). A message-driving formalism for modeling and simulation of multiagent supply chain systems. Journal of Systems Science and Systems Engineering, 20(4), 385399.

Wemmerlov, U., \& Johnson, D. J. (2000). Empirical findings on manufacturing cell design. International Journal of Production Research, 38(3), 481-507.

Yoo, T., Cho, H., \& Yücesan, E. (2010). Hybrid algorithm for discrete event simulation based supply chain optimization. Expert Systems with Applications, 37(3), 2354-2361.

Zengin, A. (2011). Modeling discrete event scalable network systems. Information Sciences, 181(5), 1028-1043.

Zengin, A., Sarjoughian, H., \& Ekiz, H. (2013). Discrete event modeling of swarm intelligence based routing in network systems. Information Sciences, 222, 81-98.

Zhao, Z., \& De Souza, R. (2000). Genetic production line-balancing for the hard disk drive industry. The International Journal of Advanced Manufacturing Technology, 16(4), 297-302. 


\section{AUTHOR BIOGRAPHIES}

JALAL JOSEPH POSSIK is a Ph.D. candidate at the University of Bordeaux, IMS Lab, Department of Production. His thesis focuses on the "Development of a configurable simulation model to evaluate the impact of Lean scenarios in a highly variable context", under the supervision of Mr. ZACHAREWICZ and Mrs. AMRANI. He received his Diploma in Computer and Communication Engineering from the Holy Spirit University, Kaslik (USEK) in 2010. He was the first to develop and lunch an automated music arranger (Java Application). In 2011, he got the MCITP Enterprise Administrator and Microsoft Exchange certifications and worked as a System Engineer at Teletrade, Lebanon. In 2012, he joined WorldNet, Lebanon where he worked as a Senior System Engineer and Virtualization Expert. He implemented VDI (Virtual Desktop Infrastructure) and Server Virtualization projects in multiple banks and big companies in Lebanon and abroad. In 2013, Jalal joined the Lebanese American University (LAU), Byblos as a System Engineer, Windows and Linux Administrator of the School of Arts and Sciences servers and machines. His email address is jalal.possik@u-bordeaux.fr.

AICHA ANNE AMRANI is an Associate Professor at the University of Bordeaux. She became a Polytechnic Engineer in 2003, she pursued her study during one year in the field of Economic Science at Moscow University. Then she got her Ph.D. in Supply Chain/Production at Bordeaux University of Science in France 2009. Her research activities at IMS Lab deal with the development of strategic models to optimize the lead times in product lifecycle during the design/development phase and Production Phase. Her interest is currently directed towards the production phase through different Lean models development. Involved in different European Projects from Automotive and Aeronautic industry since 2009, she is also a Guest Lecturer in High Business schools as: ESCE/Paris, Kedge Business School, INSEEC/Bordeaux and Arts et Métiers ParisTech. She is also a Co-Supervisor of Logistic and Industrial Engineering Master and member of International Master Team Scientists. Her email address is aicha.amrani@ims-bordeaux.fr.

GREGORY ZACHAREWICZ is an Associate Professor HDR at the University of Bordeaux (France). His research interests include discrete event $M \& S$, distributed simulation (HLA), model driven approaches, semantics aspects (short-lived ontology), and enterprise modeling (workflow, BPM, and ERP). He focused recently on Social-Organizational M\&S and Interoperability. He is involved in several M\&S conferences and journals. He has been participating in a number of French, European and transatlantic M\&S projects. His email address is gregory.zacharewicz@ims-bordeaux.fr. 